\title{
Histomorphometric Study of Intratrabecular Osteons in the Iliac Bone in Three Metabolic Bone Diseases
}

\author{
Kozo Sato and Paul D. Byers* \\ Department of Orthopaedic Surgery, Akita University \\ School of Medicine, Akita 010, and *The Institute of \\ Orthopaedics, University of London, London
}

\begin{abstract}
Sato, K. and Byers, P.D. Histomorphometric Study of Intratrabecular Osteons in the Iliac Bone in Three Metabolic Bone Diseases. Tohoku J. Exp. Med., 1994, 172 (4), 317-326 — Full-thickness biopsy specimens of iliac bones were submitted to morphometric analysis of intratrabecular osteons to study whether and how much the number and density of osteons increase in some metabolic bone diseases such as osteomalacia $(\mathrm{OM})$, primary hyperparathyroidism (PHPT) and renal osteodystrophy (ROD). The biopsies were taken from 16 patients with OM of various causes, 18 with PHPT, 12 with ROD, and from 41 control cases. All the specimens were methacrylate-embedded, sectioned undecalcified and stained with solochrome cyanine or HE. Morphometry included measurements of the density of osteons and the volume of bone and osteoid, partially assisted with a semiautomatic digital image analyzer. Intratrabecular osteons were found to be more numerous in patients with metabolic disorder than in control. It was shown by discriminant analysis that the elevated number of osteons $/ \mathrm{cm}^{2}$ tissue area contributes to the differentiation of abnormal from normal bones. The presence of blood vessels in the osteons indicated the biological significance of osteon formation which extends the metabolic surface of trabeculae, providing a basis for trabecular hypertrophy.__ intratrabecular osteons; metabolic bone disease; tunneling resorption; iliac bone; histomorphometry
\end{abstract}

Intratrabecular resorption cavities and osteons have been the subject of several studies (Jaffe 1929; Ball 1960; Garner and Ball 1966; Vaughan 1970; Pritchard 1972; Woods et al. 1972; Krempien et al. 1972; Aung et al. 1973; Lozupone 1985; Sato et al. 1986), with broad agreement about their morphology and the remodeling activity that takes place within them. Sato et al. (1986) reported a histomorphometric study on intratrabecular osteons in normal iliac cancellous bone, following an earlier quantitative analysis by Sato and Byers (1981) on dissecting resorption cavities in osteomalacia, primary hyperparathyroidism, and renal osteodystrophy. The present paper reports the histomor-

Received June 19, 1992; revision accepted for publication February 28, 1994.

Address for reprints: Kozo Sato, M.D., Department of Orthopaedic Surgery, Akita

University School of Medicine, 1-1-1 Hondo, Akita 010, Japan. 
phometric analysis of those intratrabecular channels which can be classified as osteons in the iliac cancellous bone in patients having these three metabolic bone diseases.

\section{Materials and Methods}

Full-thickness transiliac core biopsies were taken from the standard anterosuperior iliac spine bone biopsy site in 46 cases. All of these biopsies were studied as in the 1981 Sato and Byers report. They were taken out without tetracycline labeling. The 46 cases consisted of three groups as follows: 1) Eighteen cases of primary hyperparathyroidism (PHPT), with ages ranging from 19 to 73 years. 2) Sixteen cases of osteomalacia (OM) of various causes (three nutritional, three anticonvulsant induced, one each of postgastrectomy, celiac disease, Fanconi's syndrome and tumoral osteomalacia, and 6 cases recognized as OM histologically but without clinical information). The ages ranged from 16 to 79 years. The biopsies were classified as OM if the osteoid surface exceeded $30 \%$ and the osteoid volume exceeded 14\% (Sato et al. 1981; Melsen and Mosekilde 1981), and osteid seam thickness exceeded $20 \mu \mathrm{m}$ (Woods et al. 1972; Parfitt et al. 1985). 3) Twelve cases of renal osteodystrophy (ROD), all due to primary renal failure, aged between 26 and 57 years. Bone biopsy was done before hemodialysis in 10 cases and in the other two cases, during hemodialysis. Subjects who fulfilled the same criteria as those of osteomalacia were classified as osteomalacic type of ROD (Malluche and Faugere 1986) in this study.

Normal control values came from 21 male and 20 female cases, ranging in age from 13 to 72 years (mean: 38 years). Thirty-five biopsies, taken during either the treatment for coxarthrosis with total hip replacement, surgical decompression with spinal fusion for cervical and lumbar spondylosis, or osteosynthesis for femoral neck fracture, were from patients who were otherwise fit, ambulatory, and free from metabolic bone disease as proved by laboratory examinations. Six specimens were taken during autopsies from cases of sudden death (Sato et al. 1986).

The specimens were fixed in 10\% formalin, dehydrated, and embedded in methylmethacrylate. The undecalcified sections were cut with a Jung microtome and stained with either solochrome cyanine or Cole's hematoxylin eosin.

\section{The classification of intratrabecular cavities and osteons}

The feature which positively identifies a cavity as an osteon is the circumferential lamellar pattern of the mural tissue, bone or osteoid (Sato et al. 1986). These were ascribed to Class A (Fig. 1). The collagen of the wall of the remaining cavities was either randomly related (Class B), or, owing to technical difficulties, could not be accurately determined (undetermined) (Fig. 2). As described by Sato et al. (1986), Class B contains cutting cones of osteons, dissecting resorption cavities from the marrow space, and osteons in a resorption phase. The dissecting resorption cavities are tunneling and hook varieties, and are defined elsewhere (Sato and Byers 1981). The criterion to select the osteons from those cavities was based on the mean external diameter of 84 Class A osteons in normal bone (Sato et al. 1986). Any Class B cavity whose diameter was less than this mean \pm S.D. was regarded as an osteon, but qualified as Class $B$. The mean value is influenced slightly by magnification and the ocular measuring scale: in the original study a demarcation point of $160 \mu \mathrm{m}$ was given; in this study the scale unit was $17.4 \mu \mathrm{m}$, making $174 \mu \mathrm{m}$ a more convenient value.

Osteons were categorized as quiescent (Fig. 1), eroded, and osteoid (Fig. 1, 3) according to the state of the surface of the canal. An osteon both eroded and with osteoid surfaces was categorized as a wandering osteon.

\section{Morphometry}

The number of intratrabecular osteons, that of tunneling resorptions, and of hook 

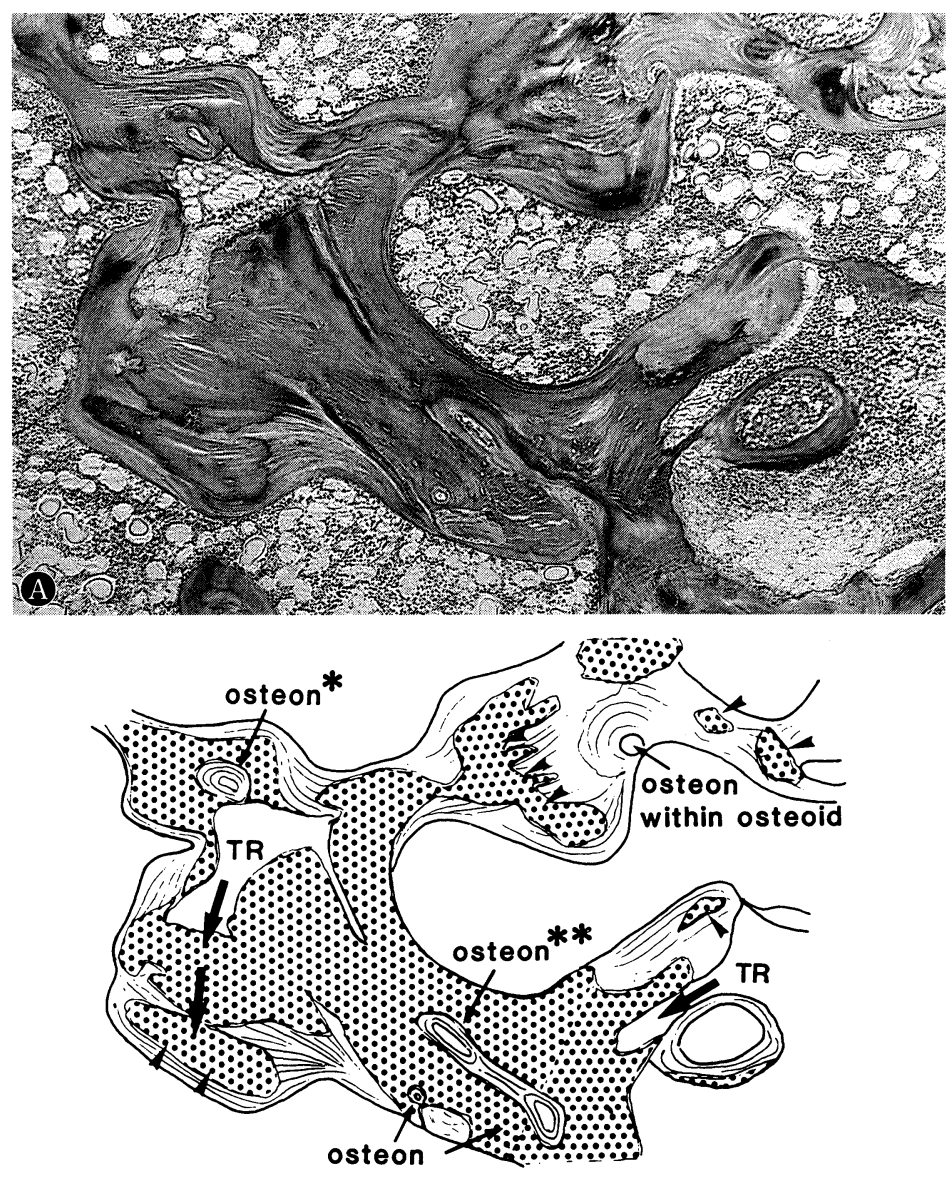

\section{calcified bone}

B

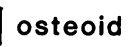

Fig. 1. Photomicrograph (A) and drawing (B) showing coexistence of tunneling resorption cavities (TR) and Class A osteons. Irregular calcification foci (arrow head) in thick osteoid layer are characteristic of advanced osteomalacia. These foci may be dissected through tunneling resorption later (TR: heavy arrow). A 47 year-old male with osteomalacia, solochromecyanine staining, $\times 100$.

*quiescent osteon, ${ }^{* *}$ osteoid osteon

resorption cavities, were counted in 20 fields of the cancellous area at a magnification of 100 using a Zeiss Integrator Plate II, an ocular grid with $10 \times 10$ grid lines. They are presented in Table 3 as intratrabecular osteons $/ \mathrm{cm}^{2}$ tissue area (Parfitt et al. 1987), intratrabecular osteons $/ \mathrm{cm}^{2}$ bone area, tunneling resorptions $/ \mathrm{cm}^{2}$ tissue area, and hook resorptions $/ \mathrm{cm}^{2}$ tissue area.

Furthermore, the same areas were subjected to the following measurements, applying the same graticule and also at the same magnification. The percent volumes for different components of bone tissue were estimated by point counting. The numbers of the crossing 

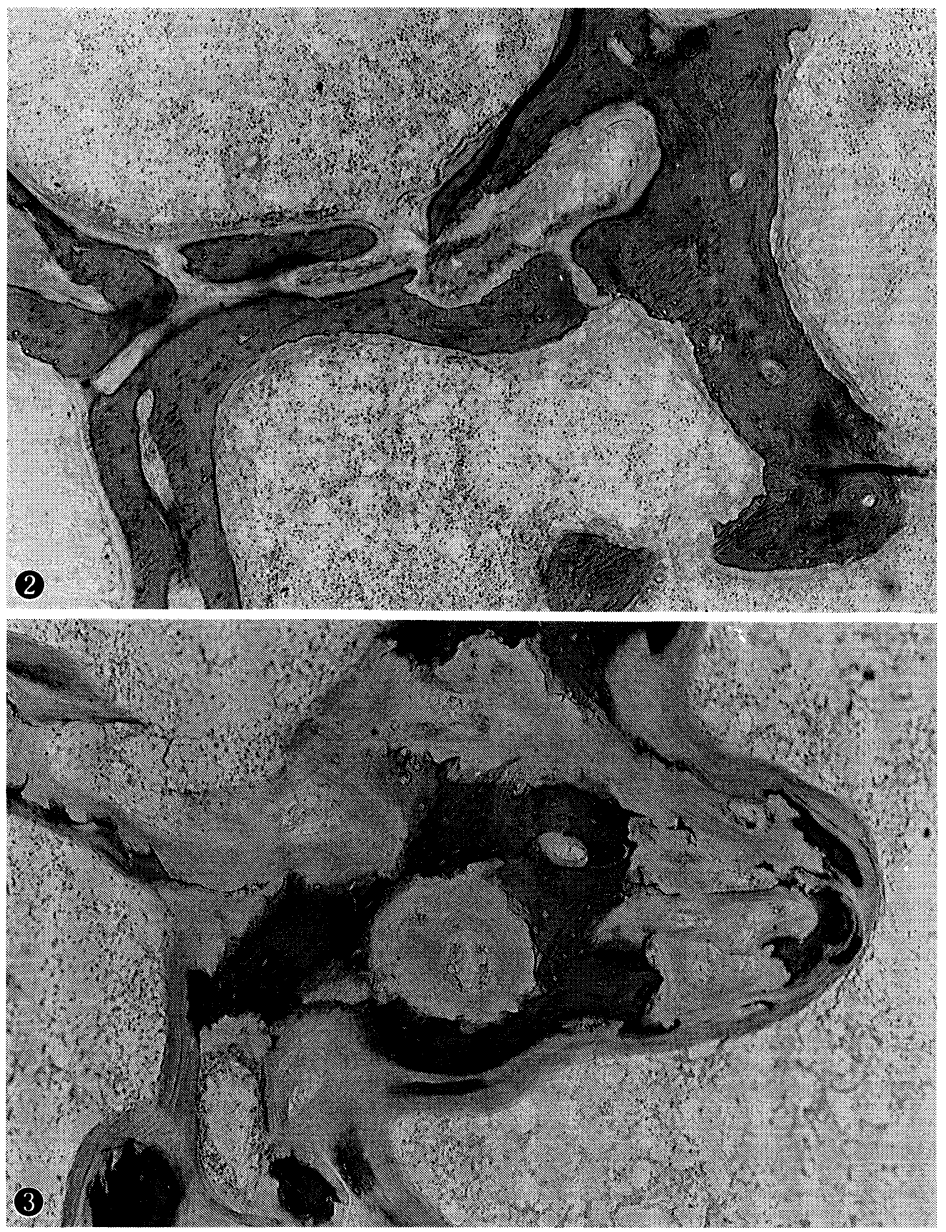

Fig. 2. Photomicrograph showing a long tunnel lined by an osteoid dissecting a core of the calcified trabeculum, and several osteons in the other branch of the trabeculum on the right. Mural tissue of these osteons show no lamellar pattern, and they were classified into Class B. This photomicrograph shows that the appearance of tunneling resorption and osteons can be affected by the direction of the cutting plane. A 53 year-old male with primary hyperparathyroidism, solochrome-cyanine staining, $\times 100$.

Fig. 3. Photomicrograph showing markedly thick trabecular bifurcation consisting of an abundant osteoid with many osteons of variable maturity. The calcified bone margins are highly irregular as the result of dissecting resorption. Every osteon is an osteoid osteon. A 46 year-old female with renal osteodystrophy, Cole's H-E staining, $\times 100$.

points of the tessellated grid which hit the trabecular bone $\left(\mathrm{n}_{\mathrm{b}}\right)$, osteoid $\left(\mathrm{n}_{0}\right)$ and bone marrow $\left(\mathrm{n}_{\mathrm{m}}\right)$ were counted. Then the bone volume $(\mathrm{BV})$, the percent volume of trabeculae in the total tissue volume, was estimated by 


$$
\mathrm{BV}=\left\{\left(\sum \mathrm{n}_{\mathrm{b}}+\sum \mathrm{n}_{\mathrm{o}}\right) /\left(\sum \mathrm{n}_{\mathrm{b}}+\sum \mathrm{n}_{\mathrm{o}}+\sum \mathrm{n}_{\mathrm{m}}\right)\right\} \times 100(\%)
$$

Similarly, the osteoid volume $(\mathrm{OV})$, the percent volume of osteoid in the bone volume, was calculated by

$$
\mathrm{OV}=\left\{\sum \mathrm{n}_{\mathrm{o}} /\left(\sum \mathrm{n}_{\mathrm{b}}+\sum \mathrm{n}_{\mathrm{o}}\right)\right\} \times 100(\%)
$$

The surface of trabeculae comprises functionally varying zones. Accordingly, the percent surfaces of the eroded (ES), osteoid (OS) and inactive (IS) zones to the total were estimated by line sampling. In a microscopic area where the grid is applied to the bone tissue, the lines of the grid come to intersect with the trabecular surfaces. The number of intersections with eroded $\left(i_{e}\right)$, osteoid $\left(i_{o}\right)$ and inactive surfaces $\left(i_{i}\right)$ were counted, and the percent of the each surface was estimated by

$$
\begin{gathered}
\mathrm{ES}=\left\{\sum \mathrm{i}_{\mathrm{e}} /\left(\sum \mathrm{i}_{\mathrm{e}}+\sum \mathrm{i}_{\mathrm{o}}+\sum \mathrm{i}_{\mathrm{i}}\right)\right\} \times 100(\%) \\
\mathrm{OS}=\left\{\sum \mathrm{i}_{\mathrm{o}} /\left(\sum \mathrm{i}_{\mathrm{e}}+\sum \mathrm{i}_{\mathrm{o}}+\sum \mathrm{i}_{\mathrm{i}}\right)\right\} \times 100(\%) \\
\mathrm{IS}=\left\{\sum \mathrm{i}_{\mathrm{i}} /\left(\sum \mathrm{i}_{\mathrm{e}}+\sum \mathrm{i}_{\mathrm{o}}+\sum \mathrm{i}_{\mathrm{i}}\right)\right\} \times 100(\%)
\end{gathered}
$$

The widths of the osteoid seams were directly measured with an ocular micrometer; 30 to 40 seams were sampled for one case. The mean trabecular thickness (Dt) was roughly estimated by

$$
\mathrm{Dt}=2 \mathrm{~S} / \mathrm{L}
$$

where $\mathrm{S}$ is the total area and $\mathrm{L}$, the perimeter length, of the trabeculae contained in a sample area. The measurement of $\mathrm{S}$ and $\mathrm{L}$ was performed using a semi-automatic computer system for histomorphometry. This system allows one to digitize microscopic images by following a small guiding light which is projected over the optical field and moves as the cursor is slided on the digitizer; the user moves the cursor so that the light in the microscopic field may follow the contours of the images of interest. A software, Cosmozone 1S (Nikon, Tokyo), was used in this measurement.

The data of morphometry and the significance of correlation were subjected to the two-tailed Student's $t$-test.

\section{RESULTS}

The total number of Class A and Class B osteons found in the cancellous bone of the 46 metabolic cases was 841: Class A, 578 (68.7\%) and Class B, 73 (8.7\%). The remaining $190(22.6 \%)$ were undetermined owing partly to an immature lamellar structure, and partly to technical difficulties. In OM and PHPT more than half of the osteons belonged to Class A (Table 1).

The distribution of quiescent, osteoid, wandering, and eroded osteons was 159 $(18.9 \%), 500(59.5 \%), 75(8.9 \%)$ and $107(12.7 \%)$, respectively. The majority of Class A osteons were either osteoid or quiescent but were predominantly the former, whereas Class B osteons were, as expected, eroded (Table 2).

Osteoid osteons in all disease categories but particularly in $\mathrm{OM}$, were numerous compared with controls (Table 2), whereas the number of quiescent osteons was much smaller. Eroded or wandering osteons accounted for $18.7 \%$ in PHPT and $39.4 \%$ in ROD (Fig. 4 ).

The distribution of osteons according to their internal diameter is shown in Fig. 5. As expected, osteons with smaller internal diameter were predominantly either quiescent or osteoid, and those with larger diameter, eroded.

Table 3 shows that the average number of osteons per unit area of tissue was 
TABLE 1. The number of intratrabecular osteons in 20 histological fields of iliac crest in 46 cases of metabolic bone disease, distributed according to class of osteon and type of disease

\begin{tabular}{cccrcr}
\hline Class & Osteomalacia & $\begin{array}{c}\text { Primary hyper- } \\
\text { parathyroidism }\end{array}$ & $\begin{array}{c}\text { Renal } \\
\text { osteo- } \\
\text { dystrophy }\end{array}$ & Total & Control \\
\hline $\begin{array}{c}\text { Number of } \\
\text { cases }\end{array}$ & 16 & 18 & 12 & 46 & 41 \\
$\mathrm{~A}^{\mathrm{a}}$ & $272(87.2 \%)$ & $173(72.1 \%)$ & $133(46.0 \%)$ & $578(68.7 \%)$ & $187(77.0 \%)$ \\
$\mathrm{B}^{\mathrm{b}}$ & $18(5.7 \%)$ & $24(10.0 \%)$ & $31(10.7 \%)$ & $73(8.7 \%)$ & $31(12.8 \%)$ \\
Undetermined & $22(7.1 \%)$ & $43(17.9 \%)$ & $125(43.3 \%)$ & $190(22.6 \%)$ & $25(10.2 \%)$ \\
Total & $312(100 \%)$ & $240(100 \%)$ & $289(100 \%)$ & $841(100 \%)$ & $243(100 \%)$ \\
\hline
\end{tabular}

${ }^{a}$ Class A osteon, lamellar collagen circumferential to the axis of the canal.

${ }^{b}$ Class B osteon, random collagen orientation around a canal.

cUndetermined, lamellar structure not classifiable owing to obliquity of section or other technical problem.

TABLE 2. The number of intratrabecular osteons in 20 histological fields of iliac crest in 46 cases of metabolic bone disease, distributed according to class of osteon and type of surface activity

\begin{tabular}{crrrr}
\hline \multirow{2}{*}{ Class } & Quiescent & \multicolumn{2}{c}{ State of osteons } & \multirow{2}{*}{ Eroded } \\
\cline { 3 - 4 } & & \multicolumn{1}{c}{ Osteiod } & Wandering & \\
\hline A & $117(20.2 \%)$ & $450(77.9 \%)$ & $6(1.0 \%)$ & $5(0.9 \%)$ \\
B & $7(9.6 \%)$ & $0(0 \%)$ & $28(52.1 \%)$ & $38(38.3 \%)$ \\
Undetermined & $35(18.4 \%)$ & $50(26.3 \%)$ & $41(21.6 \%)$ & $64(33.7 \%)$ \\
Total & $159(18.9 \%)$ & $500(59.5 \%)$ & $75(8.9 \%)$ & $107(12.7 \%)$ \\
Controls & $154(63.4 \%)$ & $45(18.5 \%)$ & & $44(18.1 \%)$ \\
\hline
\end{tabular}

${ }^{a}$ wandering, with both osteoid and eroded surfaces.

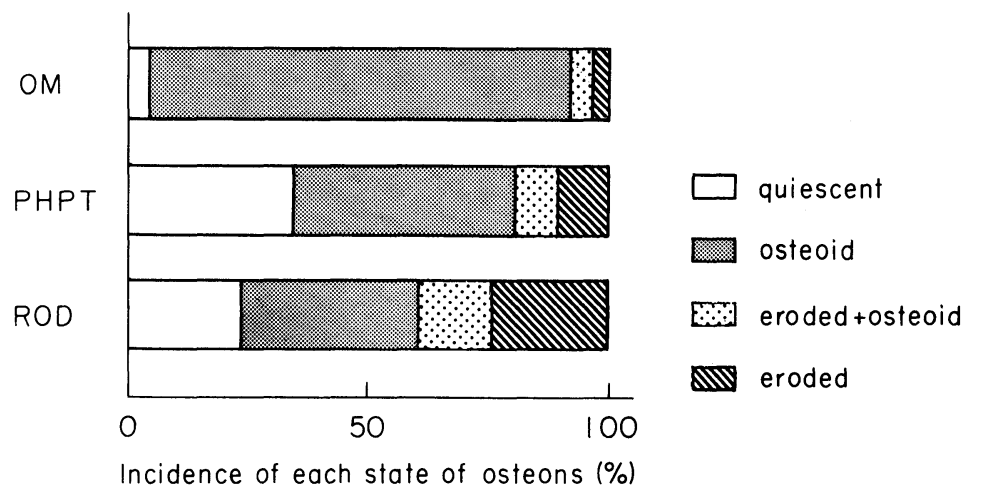

Fig. 4. Percentage incidence in each disease category of intratrabecular osteons classified according to the surface state. Osteoid osteons are remarkably numerous in osteomalacia. 


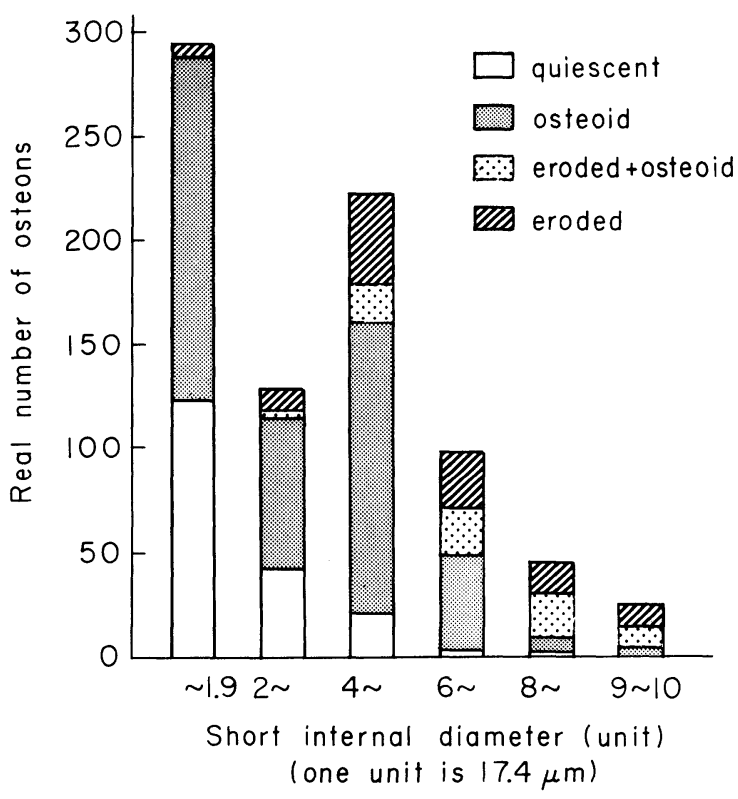

Fig. 5. The distribution of all osteons by size. Osteons with a small internal diameter are either quiescent or osteoid, while those with a large diameter are eroded, as would be expected.

largest in osteomalacic cases of ROD, followed by OM. The mean number of osteons per bone area roughly reflected that per tissue area, and in all disease categories it was significantly greater than in the controls. The groups with numerous osteons also had a large amount of bone, and thicker trabeculae. The number of osteons was generally much larger than that of tunneling and hook resorptions in all groups. Tunneling resorptions were equally numerous in each disease category, whereas hook resorptions were recognized most frequently in non-osteomalacic ROD.

The mean number of osteons per $\mathrm{cm}^{2}$ of tissue of each case is plotted against the bone volume in Fig. 6, where the normal range obtained in the previous work (Sato and Byers 1981) is also illustrated. The correlation of the number of osteons with bone volume was found to be significant not only when calculated for the individual disease categories but when the whole data were pooled $(\mathrm{r}=0.562$, $p<0.05$ for $\mathrm{OM}$; $\mathrm{r}=0.513, p<0.05$ for PHPT; $\mathrm{r}=0.860, p<0.001$ for ROD, and collectively $\mathrm{r}=0.640, p<0.01$ ) (Fig. 6). Also its correlation with the trabecular thickness was significant in ROD $(r=0.583, p<0.05)$ and collectively $(r=0.425$, $p<0.01$ ), and it was marginally significant in $\mathrm{OM}$. The correlation with the number of tunneling resorptions was significant in $\mathrm{OM}(\mathrm{r}=0.643, p<0.01)$ and $\mathrm{ROD}(\mathrm{r}=0.815, p<0.001)$, but with hook resorption it was significant only in OM $(\mathrm{r}=0.676, p<0.01)$. 
TABLE 3. Results of histomorphometric study

\begin{tabular}{|c|c|c|c|c|c|c|}
\hline & \multirow{2}{*}{$\mathrm{OM}^{\mathrm{a}}$} & \multirow{2}{*}{$\mathrm{PHPT}^{\mathrm{b}}$} & \multicolumn{3}{|c|}{$\mathrm{ROD}^{\mathrm{c}}$} & \multirow{2}{*}{ Contro } \\
\hline & & & non-om ${ }^{d}$ & $\mathrm{om}^{\mathrm{e}}$ & Total & \\
\hline Number of cases & 16 & 18 & 7 & 5 & 12 & 41 \\
\hline $\begin{array}{l}\text { Number of osteon/unit } \\
\text { area o tissue }\left(\mathrm{cm}^{2}\right)\end{array}$ & $\begin{array}{c}53.0 \\
(38.7)\end{array}$ & $\begin{array}{c}31.2 \\
(16.5)\end{array}$ & $\begin{array}{l}30.8 \\
(25.8)\end{array}$ & $\begin{array}{c}60.3 \\
(34.4)\end{array}$ & $\begin{array}{c}43.1 \\
(32.0)\end{array}$ & $\begin{array}{l}8.8 \\
(7.4)\end{array}$ \\
\hline $\begin{array}{l}\text { Number of osteon/unit } \\
\text { area of bone }\left(\mathrm{cm}^{2}\right)\end{array}$ & $\begin{array}{c}165.6 \\
(116.6)\end{array}$ & $\begin{array}{l}124.0 \\
(69.9)\end{array}$ & $\begin{array}{c}165.8 \\
(125.3)\end{array}$ & $\begin{array}{l}205.8 \\
(58.4)\end{array}$ & $\begin{array}{c}182.5 \\
(101.2)\end{array}$ & $\begin{array}{c}48.2 \\
(36.7)\end{array}$ \\
\hline $\begin{array}{l}\text { Number of tunneling } \\
\text { resorption/unit area } \\
\text { of tissue }\left(\mathrm{cm}^{2}\right)\end{array}$ & $\begin{array}{c}6.2 \\
(7.0)\end{array}$ & $\begin{array}{c}6.7 \\
(8.9)\end{array}$ & $\begin{array}{l}3.6 \\
(4.5)\end{array}$ & $\begin{array}{l}10.3 \\
(6.4)\end{array}$ & $\begin{array}{c}6.4 \\
(6.3)\end{array}$ & $\begin{array}{c}0.3 \\
(0.6)\end{array}$ \\
\hline $\begin{array}{l}\text { Number of hook } \\
\text { resorption/unit area } \\
\text { of tissue }\left(\mathrm{cm}^{2}\right)\end{array}$ & $\begin{array}{c}7.4 \\
(6.7)\end{array}$ & $\begin{array}{l}3.8 \\
(3.5)\end{array}$ & $\begin{array}{l}17.8 \\
(6.4)\end{array}$ & $\begin{array}{c}6.1 \\
(3.9)\end{array}$ & $\begin{array}{l}13.0 \\
(8.0)\end{array}$ & $\begin{array}{l}1.9 \\
(2.2)\end{array}$ \\
\hline $\begin{array}{l}\text { Bone volume } \\
\text { ( } \% \text { of tissue volume) }\end{array}$ & $\begin{array}{c}29.5 \\
(10.5)\end{array}$ & $\begin{array}{l}23.9 \\
(7.3)\end{array}$ & $\begin{array}{l}16.7 \\
(6.7)\end{array}$ & $\begin{array}{c}28.0 \\
(10.6)\end{array}$ & $\begin{array}{l}21.4 \\
(9.9)\end{array}$ & $\begin{array}{l}15.8 \\
(6.6)\end{array}$ \\
\hline $\begin{array}{l}\text { Osteoid volume } \\
\text { ( } \% \text { bone volume })\end{array}$ & $\begin{array}{c}38.9 \\
(17.5)\end{array}$ & $\begin{array}{l}11.8 \\
(8.0)\end{array}$ & $\begin{array}{c}4.6 \\
(2.9)\end{array}$ & $\begin{array}{c}34.5 \\
(10.5)\end{array}$ & $\begin{array}{c}17.1 \\
(16.8)\end{array}$ & \\
\hline $\begin{array}{l}\text { Osteoid surface } \\
\quad(\% \text { bone surface })\end{array}$ & $\begin{array}{c}86.0 \\
(10.8)\end{array}$ & $\begin{array}{c}56.0 \\
(15.4)\end{array}$ & $\begin{array}{l}32.0 \\
(15.2)\end{array}$ & $\begin{array}{l}83.6 \\
(7.8)\end{array}$ & $\begin{array}{c}53.5 \\
(29.2)\end{array}$ & \\
\hline $\begin{array}{l}\text { Osteoid thickness } \\
(\mu \mathrm{m})\end{array}$ & $\begin{array}{c}41.2 \\
(24.9)\end{array}$ & $\begin{array}{l}15.2 \\
(3.9)\end{array}$ & $\begin{array}{l}12.8 \\
(4.3)\end{array}$ & $\begin{array}{c}37.5 \\
(12.9)\end{array}$ & $\begin{array}{c}23.1 \\
(15.3)\end{array}$ & \\
\hline $\begin{array}{l}\text { Trabecular thickness } \\
\qquad(\mu \mathrm{m})\end{array}$ & $\begin{array}{l}187.4 \\
(58.8)\end{array}$ & $\begin{array}{l}136.4 \\
(38.8)\end{array}$ & $\begin{array}{l}127.4 \\
(18.0)\end{array}$ & $\begin{array}{l}155.2 \\
(44.4)\end{array}$ & $\begin{array}{l}139.0 \\
(33.1)\end{array}$ & \\
\hline
\end{tabular}

Values are given as mean $(+/-\mathrm{SD})$

${ }^{\mathrm{a} O M}$, osteomalacia; ${ }^{\mathrm{P}} \mathrm{PHPT}$, primary hyperparathyroidism; ${ }^{\mathrm{c}} \mathrm{ROD}$, renal osteodystrophy; ${ }^{d}$ non-om, non-osteomalacic ; ${ }^{e}$ om, osteomalacic.

\section{Discussion}

Intratrabecular osteons are prevalent in the three metabolic bone diseases studied (OM, PHPT and ROD), particularly in the volume-increasing conditions of OM and osteomalacic ROD. The obvious mechanism for this prevalence is tunneling resorption from the trabecular surface with subsequent circumferential osteoid deposition on the surfaces. The significant correlation of the number of osteons with the trabecular width and the higher prevalence in more massive structures reconfirmed our earlier study (Sato et al. 1986), suggesting that the osteons are formed so as to meet the metabolic need of thickened trabeculae by extending the surface available for remodeling and gas exchange with the blood flow within the canal. But we postulate an additional significance for this phenomenon: it compensates for the loss of surface available for resorption as the result of increased osteoid coverage (Sato and Byers 1981). In Table 3 there is a close correlation between the osteoid surface and the number of tunneling resorptions; an increased osteoid implies the surface available for resorption correspondingly narrowed. 


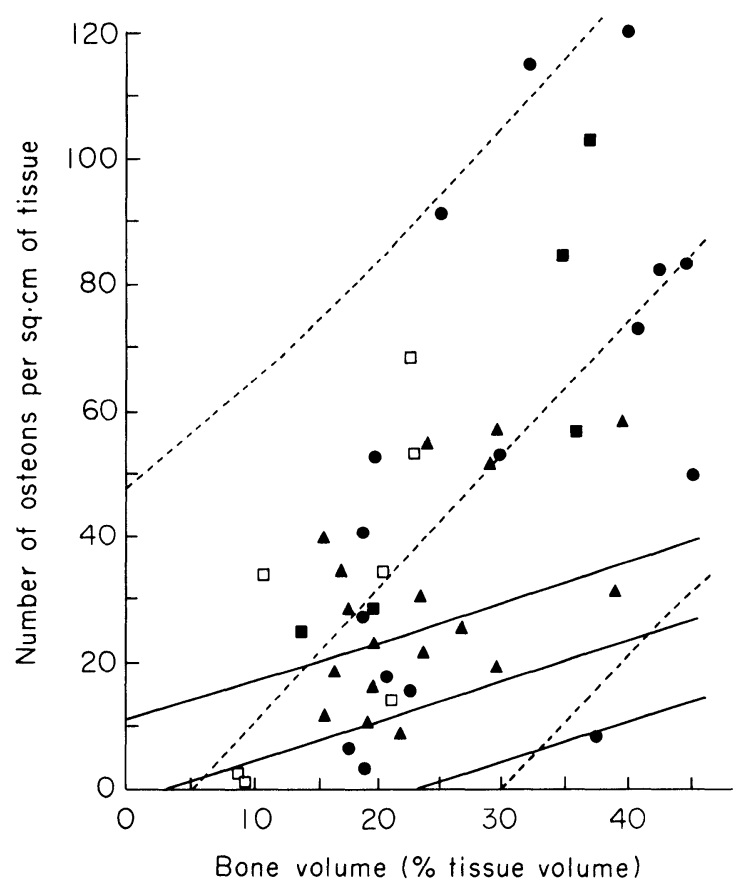

Fig. 6. Correlation of the mean number of osteons $/ \mathrm{cm}^{2}$ tissue with bone volume ( $\%$ tissue) for 46 cases of metabolic bone disease (dotted lines) and 41 controls (solid lines). The demarcation curves are at the $95 \%$ confidence interval. - osteomalacia; \ hyperparathyroidism; $\square$ renel osteodystrophy.

Of further interest is the way numerous osteons form in a thick trabecula in the osteomalacic state, as shown in Figs. 1 and 3. Thick osteoid layers cover almost all trabecular surfaces, so that dissecting resorption is not likely to begin there. It is a common finding that irregular foci of calcification develop within the thick osteoid, and that they enlarge to merge with the adjacent calcified bone, in which an osteon is usually present. It is more likely that tunneling resorption extends from the osteon into the newly calcified focus as a cutting cone and is followed by the formation of Class A osteons.

Discriminant analysis indicates that the frequency of intratrabecular osteons is a useful indicator by which metabolic bone diseases such as OM, PHPT and ROD can be distinguished from the normal bone. The discriminant function calculated was: $1.64542-0.06371 \mathrm{X}$, where $\mathrm{X}$ is the number of osteons $/ \mathrm{cm}^{2}$ tissue. The F-value was 46.274. The accuracy of discrimination was $97.6 \%$ for the normal bone, and $65.2 \%$ for the metabolic bone disease cases. When discriminant score is $0, \mathrm{X}$ is 25.8. Accordingly, when a bone specimen is proved to have more than 25.8 osteons $/ \mathrm{cm}^{2}$ tissue, a diagnosis of abnormal bone may be justified. 


\section{References}

1) Aung, T., Williams, E.D., Carrol, R.N.P. \& Shackman, R. (1973) Quantitative histopathological studies of the effect of hemodialysis of renal osteodystrophy. In: Clinical Aspects of Metabolic Bone Disease, edited by B. Frame, A.M. Parfitt \& H. Duncan, Excerpta Medica, Amsterdam, pp. 601-603.

2) Ball, J. (1960) Disease of bone. In: Recent Advances in Pathology, edited by C.V. Harrison, J \& A Churchill Ltd., London, pp. 293-338.

3) Garner, A. \& Ball, J. (1966) Quantitative observation on mineralised and unmineralised bone in chronic renal azotaemia and intestinal malabsorption syndrome. $J$. Pathol. Bacteriol, 91, 545-561.

4) Jaffe, H.L. (1929) The vessel canals in normal and pathologic bone. Am. J. Pathol., 5, 323-337.

5) Krempien, B., Ritz, E., Beck, U. \& Keilbach, H. (1972) Osteopathy in maintenance hemodialysis (micromorphometric and microradiographic studies with correlations to serum parathyroid hormone and calcitonin levels). Virchows Arch. (A], 357, 257-274.

6) Lozupone, E. (1985) The structure of the trabeculae of cancellous bone. 1. The calcaneus. Anat. Anz. Jena., 159, 211-229.

7) Malluche, H.H. \& Faugere, M.C. (1986) Renal bone disease. In: Atlas of Mineralized Bone Histology, Karger, Barsel, pp. 70-103.

8) Melsen, F. \& Mosekilde, L. (1981) The role of bone biopsy in the diagnosis of metabolic bone disease. Orthop. Clin. North Am., 12, 571-602.

9) Parfitt, A.M., Podenphant, J., Villanueva, A.R. \& Frame, B. (1985) Metabolic bone disease with and without osteomalacia after intestinal by-pass surgery: A bone histomorphometric study. Bone, 6, 211-220.

10) Parfitt, A.M., Drezner, M.K., Glorieux, F.H., Kanis, J.A., Malluche, H., Meunier, P.J., Ott, S.M. \& Recker, R.R. (1987) Bone histomorphometry: Standardization of nomenclature, symbols, and units. J. Bone Mineral Res., 2, 595-610.

11) Pritchard, J.J. (1972) General histology of bone. In: The Biochemistry and Physiology of Bone, edited by G.H. Bourne, Vol. 1. Academic Press, New York, pp. 1-20.

12) Sato, K. \& Byers, P. (1981) Quantitative study of tunneling and hook resorption in metabolic bone disease. Calcif. Tissue Int., 33, 459-466.

13) Sato, K., Wakamatsu, E., Sato, T., Honma, T., Kotake, H. \& Byers, P. (1986) Histomorphometric study of trabecular channels in normal iliac bone. Calcif. Tissue Int., 39, 2-7.

14) Vaughan, J.M. (1970) Bone as a tissue. In: The Physiology of Bone, Clavendon Press, Oxford, pp. 1-22.

15) Woods, C.G., Bishop, M.C. \& Nicholson, G.D. (1972) Bone histological changes occurring after hemodialysis treatment for chronic renal failure. J. Pathol., 107, 137143. 